\title{
CAMBIO CLIMÁTICO Y HUELLA ECOLÓGICA
}

Flor de María Madrid de Mejía ${ }^{1}$

La huella ecológica mide las exigencias que la humanidad impone sobre la naturaleza.

\section{RESUMEN}

La huella ecológica es un índice de sostenibilidad, con ella podemos identificar los impactos ambientales más significativos y evaluar rápidamente el impacto global de individuos, comunidades, ecosistemas o naciones. Constituye un elemento en el sistema de gestión, es una herramienta de reflexión y enseñanza que ha probado ser útil en aulas de clase, evaluación de proyectos entre otros. Conocer el déficit ecológico de nuestras instituciones nos ayudará a proponer alternativas de solución para poder alcanzar la sustentabilidad

Palabras Claves: Huella Ecológica, Sustentabilidad.

\begin{abstract}
The ecological footprint is a sustainability index, with it we can identify the most significant environmental impacts and quickly assess the overall impact of individuals, communities, ecosystems or nations. It is an element management system is a tool for reflection and learning that has proven useful in classrooms, project evaluation among others. Knowing the ecological deficit of our institutions will help us to propose alternatives solutions to achieve sustainability
\end{abstract}

Keywords: Ecological Footprint, Sustainability

1 Facultad de Ciencias Biológicas - Instituto de Recursos Naturales y Ecología, Universidad Ricardo Palma 
A final de cada año se celebra una conferencia de las partes (COP), en la que ministros y delegados de diferentes países tratan de llegar a un acuerdo para progresar en la lucha frente al Calentamiento Global. La COP 20 fue Latinoamericana y el Perú fue sede de esta conferencia tan importante de la ONU sobre Cambio Climático, es el tercer país de América Latina en albergar la COP, luego de Buenos Aires - Argentina COP4 y COP10 y Cancún - México COP 16 antes de la reunión crucial de París en diciembre del 2015.

Para la contabilidad mundial del carbono, el mundo es un solo país, las emisiones de gases de efecto invernadero se mezclan libremente en la atmósfera. Para efectos del Cambio climático da lo mismo que una tonelada de $\mathrm{CO}_{2}$ provenga de un automóvil o de la perdida de sumideros de carbono en los bosques tropicales. Si bien cada tonelada de $\mathrm{CO}_{2}$ tiene el mismo peso, la contabilidad global revela grandes variaciones en su procedencia verificadas por la huella ecológica que dejan las emisiones de $\mathrm{CO}_{2}$ y la diferencia en la profundidad de dichas huellas.

La Huella Ecológica actual de la tierra sobrepasa en un 33\% su capacidad regenerativa. Es decir, hoy consumimos en un año lo que el planeta puede renovar de modo sostenible en dieciséis meses.

La biocapacidad del planeta es de 1,8 Ha/persona. Las naciones desarrolladas, pese a sus avances tecnológicos, tienen huellas que exceden la capacidad del planeta.

De acuerdo al mapa donde se muestra la huella ecológica producida por cada país del mundo, Estados Unidos es el emisor más grande de $\mathrm{CO}_{2}$, por ejemplo, la huella per cápita de EE.UU. es de 9,6 Ha. Solo entre los 5 primeros países (Estados Unidos, Federación Rusa, China, India y Japón) se produce la mitad de la contaminación que produce el mundo. En conjunto los países de ingresos bajos tienen una tercera parte de la población mundial que representa el $7 \%$ de las emisiones de $\mathrm{CO}_{2}$.

El proyecto sobre Huella ecológica, nació en la Universidad de British Columbia, Canadá, y sus creadores fueron Mathis Wackernagel y William Rees. Quienes definieron La Huella Ecológica, como: “El área de territorio ecológicamente productivo (cultivos, pastos, bosques o ecosistemas acuáticos) necesaria para producir los recursos utilizados y para asimilar los residuos producidos por una población definida con un nivel de vida específico indefinidamente, donde sea que se encuentre esta área" 
Esta teoría fue formulada en 1996 en la School for Community and Regional Planning (Escuela para la planificación comunitaria y regional) de la Universidad de la Columbia Británica. Se encarga de registrar el consumo en diferentes categorías (cultivos, pastos, bosques, mar, terreno construido y áreas de absorción de $\mathrm{CO}_{2}$ ) y transformarlo en la superficie biológica productiva apropiada a través de índices de productividad. Para hallar el resultado se acuñó el concepto de "huella individual" para cada recurso. Así, el área apropiada per cápita para la producción de cada artículo de consumo es igual al consumo medio anual de ese artículo dividido entre su productividad media o rendimiento.

\section{INDICADOR AMBIENTAL}

La huella ecológica es un indicador ambiental de carácter integrador del impacto que ejerce una determinada comunidad humana, país, región o ciudad sobre su entorno, es una forma de medir cuanto utiliza el ser humano de la naturaleza para satisfacer sus necesidades y sus estilos de vida, es una medida de superficie que se suele expresar en hectáreas globales per capita al año ha/cap/año (hectáreas/ capacidad de carga/ año) si realizamos el cálculo para un habitante, o bien, en hectáreas si el cálculo se refiere al conjunto de la comunidad estudiada.

La metodología de cálculo de este indicador ambiental tiene que valorar necesariamente los recursos consumidos y los residuos generados por una población determinada con un modo de vida específico en un área concreta.

La Huella Ecológica es un indicador de sostenibilidad que responde a la pregunta de: Cuanto de los recursos de la tierra requieres para llevar a cabo tu vida? Es decir el impacto que tiene nuestro estilo de vida sobre el planeta

En el cálculo de la huella ecológica, se contabiliza el consumo de la población en distintas categorías: Cultivos, pastos, bosques, mar productivo, terreno construido, área de absorción de $\mathrm{CO}_{2}$ que es la superficie de bosque necesaria para la absorción de la emisión de $\mathrm{CO}_{2}$ debida al consumo de combustibles fósiles para la producción de energía 
La huella ecológica individual para cada una de las seis categorías se calcula mediante la fórmula:

\section{$\mathrm{Hi}=c i=\underline{\text { Consumo medio anual del articulo i (Kg/cap) }}$ \\ Ri Rendimiento medio del articulo i ( $\mathrm{Kg} / \mathrm{Ha}$ )}

La huella ecológica per capita es la suma de las huellas ecológicas individuales de cada recurso.

$$
\text { he }=\sum \text { hi }
$$

La huella ecológica global de una región o un país es la suma de la huella ecológica de sus habitantes.

\section{HG $=$ he $\times n^{0}$ de habitantes}

La huella ecológica de la humanidad excede ya en 33\% la biocapacidad de renovación del planeta, por ello, se debe hacer propuestas de políticas que orienten a nuestra comunidad hacia una mayor eficiencia y reducción en el consumo de energía y promover el uso de energías alternativas y renovables, impulsar, el desarrollo de las ciudades sostenibles, promover que los arquitectos orienten sus trabajos y a sus clientes hacia el diseño de oficinas o viviendas que por el propio diseño ahorren energía, ello es la arquitectura bioclimática, es lograr la construcción de edificios y ciudades que produzcan energía en lugar de consumirla, que purifiquen el aire en lugar de contaminarlo y que reúsen los materiales utilizados, con ello reduciremos las emisiones, obtendremos beneficios económicos por el ahorro y reduciremos el déficit energético de nuestro país.

Mathis Wackernagel, Director Ejecutivo de Global Footprint Network, explicó que en el caso del Perú, se tiene dos veces la capacidad de recursos de los que se utiliza, pero que sin embargo, Lima tiene déficit pues gasta tres veces más de lo que tiene.

En el Perú, la Huella Ecológica, arroja un promedio por persona de las ciudades, igual a 1,47 Ha/hab/año. Si consideramos el suelo productivo disponible en el Perú, esta cifra nos podría hacer pensar que contamos con un superávit ecológico ya que disponemos de mucho suelo para nuestro 
desarrollo, o de mucho bosque para que reciba nuestras emisiones de $\mathrm{CO} 2$, pero si analizamos la huella ecológica desde el punto de vista de las ciudades, asumiendo que el área considerada como construida representa a las ciudades, entonces tendríamos un déficit ecológico.

En el caso de los países con ingresos medio el promedio de la Huella ecológica es de 1.9 hectáreas. Esta huella ecológica de más de un millón y medio de hectáreas es lo que debemos asumir anualmente por el consumo de combustibles derivados del petróleo y que va en aumento con el aumento del parque automotor y sus emisiones.

El Perú pertenece a ese grupo pero su consumo es de 1.4 hectáreas por persona. El asunto es más interesante si se repara en que la biocapacidad de nuestro territorio es de 3.8 hectáreas por persona. Es decir, estamos entre quienes no son deficitarios y, más aún, gozamos de una importante "reserva".

La Huella ecológica indica que 0.09 hectáreas de bosque per cápita son utilizadas en el Perú, mientras que la biocapacidad del país es de 2.45 hectáreas. Se aprovechan 0.12 hectáreas de recursos pesqueros por persona, siendo su disponibilidad es más del triple, 0.39 .

\section{CAPTURA DE CARBONO EN LOS BOSQUES}

Para el cálculo de la Huella Ecológica el costo energético lo podemos expresar en las hectáreas de bosque necesarias para absorber el $\mathrm{CO}_{2}$ generado por las emisiones atmosféricas en el consumo de energía.

La capacidad de un bosque de actuar como sumidero de carbono depende de diversos aspectos, tales como el tipo de bosque, si es primario o secundario, si ha sido manejado, las especies que lo habitan, éstos y otros factores van a determinar cuánto $\mathrm{CO}_{2}$ puede capturar el bosque por hectárea y fijar el carbono en el proceso de su desarrollo. Por ello, para calcular la cantidad de $\mathrm{CO}_{2}$ que puede absorber un determinado bosque, se debe realizar un estudio específico y profundo sobre sus características y así estimar su capacidad de absorción. Para el cálculo de la fijación de carbono a partir de la captura de $\mathrm{CO}_{2}$ atmosférico es importante considerar que para fijar 1 tonelada de carbono (tc) se deben absorber 3,7 toneladas de dióxido de carbono $\left(\mathrm{tCO}_{2}\right),\left(1 \mathrm{tc}=3,7 \quad \mathrm{tCO}_{2}\right)$ considerando que un bosque en promedio absorbe $10 \mathrm{tCO}_{2}$ /año y un árbol captura $1,5 \mathrm{tde} \mathrm{CO}_{2}$ durante toda su vida. 


\section{EL COSTO ENERGÉTICO}

Para la producción de los bienes y servicios que utilizamos se consume energía, y dicho consumo tiene un costo en el uso de los recursos naturales y en los impactos ambientales. Uno de los mayores costos por impacto al ambiente son las emisiones de $\mathrm{CO}_{2}$, que es el principal gas de efecto invernadero y que su elevada producción contribuye al calentamiento global y el consecuente cambio climático. Por ello que el costo energético muchas veces se calcula en emisiones de $\mathrm{CO}_{2}$ y se consideran también los sumideros de carbono para absorber el carbono de dichas emisiones.

\section{Como reducir nuestra huella ecológica}

- Ahorrar agua

- Apostar por energías renovables

- Consumir alimentos de producción local

- Participar en campañas de sensibilización

- Utilizar focos ahorradores de bajo consumo

- Evitar los productos con demasiado embalaje

- Sembrar una determinada cantidad de árboles

- Caminar, hacer uso de bicicleta o transporte publico

- Reducir, Reusar y Reciclar nuestra basura en este orden de prioridad

- Proponer a los políticos la reducción de emisiones de CO2, utilizando energías renovables

\section{Reflexiones sobre la huella ecológica}

- Potente herramienta pedagógica para la sensibilización.

- Permite modelar cambios de hábitos y cambios tecnológicos y ver su influencia.

- Visualiza la dependencia de una población para mantener un determinado nivel de consumo

- Identifica en un solo numero el impacto que provoca una población sobre un ecosistema

- Refleja la injusticia social en el uso de los recursos del planeta según los diferentes estilos de vida.

La huella ecológica muestra que existe una relación directa entre los hábitos, estilos de vida y los problemas medioambientales. El cálculo de la Huella ecológica nos ayuda a darnos cuenta de la magnitud del daño 
que estamos causando al planeta y visualizar el impacto generado por cada individuo. Para reducir la huella ecológica es imprescindible que el mundo desarrollado comience a cambiar sus hábitos de consumo y nosotros no profundicemos nuestra huella.

La motivación por emprender medidas urgentes de mitigación y adaptación, nace de la preocupación por el bienestar de las generaciones futuras.

Ahora que está en vigencia el Protocolo de Kyoto, el cual obliga a reducir las emisiones de gases de efecto invernadero, conocer el impacto del consumo de energía en el Cambio climático, ayuda a que los gobiernos puedan programar políticas que contribuyan a cumplir los compromisos adquiridos y así evitar un Cambio Climático peligroso, proyectando la adaptación al mismo.

\section{REFERENCIAS BIBLIOGRÁFICAS}

1. FAO, Proyectos Forestales de Fijación de Carbono, www.fao.org/ documents/show_cdr.asp?url_file=/docrep/006/j2053s/j2053s09

2. Hails, C; Loh, J ; Godfinger, S. 2006 Living Planet report. WWF. USA

3. Huella ecológica y sostenibilidad www.cfnavarra.es/medioambiente/agenda/Huella/EcoSos.htm

4. Klein, N. 2014 *Esto lo cambia todo. Capitalismo vs el Clima* Allen Lane, London

5. López Álvarez N. 2009. Metodología para el Cálculo de la huella ecológica en universidades. Universidad de Santiago de Compostela. Oficina de Desarrollo Sostenible

6. Miranda, L. 2008 Construyendo ciudades para la vida: aportes a la construcción sostenible en el Perú. Ciudades para la vida.

7. Peña. Juan 2009 El Poder ecológico de las naciones: la biodiversidad de la Tierra como un nuevo marco para la cooperación internacional

8. PNUD Informe sobre Desarrollo Humano 2007 - 2008. La lucha contra el Cambio Climático: Solidaridad frente a un mundo dividido

9. Wackernagel, M.; Rees, W. 2001 Nuestra huella ecológica: Reduciendo el impacto humano sobre la tierra. Ed, LOM. Santiago de Chile 
10. www.Redefining Progress.org, 2008

11. www.tierramerica.org/consumidor/huella.shtml

12. www.footprintnetwork.org/en/index.php/GFN/page/africa 